\title{
Thermal insulation shaped mineral wool products with effective binder
}

\author{
Kazbek Ivanov ${ }^{1, *}$, Aleksey Zhukov ${ }^{1}$, Ekaterina Bobrova $^{2}$, Ekaterina Zhukova $^{1}$, and Kirill \\ Wako $^{1}$ \\ ${ }^{1}$ Moscow State University of Civil Engineering (NRU MGSU), 26 Yaroslavskoye Sh., Moscow, \\ 129337, Russia \\ ${ }^{2}$ High School of Economics., 20 Myasnitskaya St, Moscow, 10100, Russia
}

\begin{abstract}
Thermal insulation of pipelines for the centralized hot water supply generally made by cylinders or mats based on a mineral wool. The criterion of an efficiency of the thermal insulation system is its technical properties, a durability and a cost of production. Modern thermal insulation products made from the mineral stone fiber possessing high chemical resistance. A structure of the products is such that the fiber is in a strong bond and has a volume-oriented state. Complicated bound structure gives to the product additional strength characteristics, and it is fixed due to curing of a binder. The substances having high resistance in the cured state are used as a binder. Accordingly, a reserve for increased durability is the completeness of curing of the binder. Which, in turn, depends on the organization of the process of thermal treatment. Cost reduction caused by the use of a binder with a curing temperature of up to $150^{\circ} \mathrm{C}$. The possibility of justifying an application of epoxy modified binder with a latent hardener is given in the article, and the methodology of the choice of parameters of the mode of thermal treatment of mineral wool cylinders with this type of binder is also stated. The methods are based on graphics intended for selecting parameters of thermal treatment of mineral wool cylinders obtained as a result of engineering interpretation of mathematical models with empirical coefficients, and also a computer program for calculation based on the algorithm developed by the authors.
\end{abstract}

\section{Introduction}

The economy of energy in the course of its delivery is especially actual for economic objects which activity is provided with stations of the centralized preparation of heat. The distances measured by kilometers do the amount of losses of heat proportioned to the total amount of delivery [1-6]. The issue is resolved by use of the insulating systems including effective thermal-insulating materials and ways of their protection. Heat insulation of objects of housing and communal services, and, in the first turn of pipelines of hot water supply is

*Coresponding author: petrel@,bk.ru 
generally made by mineral wool products and in particular cylinders on the basis of stone wool [7-14].

Mineral wool cylinders produce by two methods: either on spirally wound, or cutting technologies. The most efficient result can be achieved by spirally wound technology. In this case, the continuity of a mineral wool matrix is not broken by cuts, and layer-by-layer coiling is an additional factor of an interlacing of fibers in a product, that is create the structure with high degree of an interlacing of fibers.

The cylinders based on spirally wound technology is produce in two basic densities of 80 and $120 \mathrm{~kg} / \mathrm{m} 3$ (tab. 1). The cylinders covered (masked) with the reinforced aluminum foil have a self-adhesive overlap of a foil. It significantly simplifies mounting. The foil on the cylinder serves as a vapor barrier layer on cold pipelines, and indoors serves as a covering material. The external pipelines, thermal insulation must be protected by either fiberglass or the metal casings fixed on bandages or a wire [15-18]. Cylinders can be used on surfaces with a temperature from -180 to $+650{ }^{\circ} \mathrm{C}$.

Table 1. Physical and technology characteristics

\begin{tabular}{|l|c|c|}
\hline \multicolumn{1}{|c|}{ Characteristics } & Cylinder 80 & Cylinder 120 \\
\hline Density, $\mathrm{kg} / \mathrm{m}^{3}$ & 80 & 120 \\
\hline Heat conductivity, $\mathrm{W} /(\mathrm{m} \cdot \mathrm{K})$ & & 0.035 \\
\hline - at $10^{\circ} \mathrm{C}$ & 0.033 & 0.037 \\
\hline - at $25^{\circ} \mathrm{C}$ & 0.036 & 0.048 \\
\hline - at $125^{\circ} \mathrm{C}$ & 0.046 & 0.087 \\
\hline - at $300^{\circ} \mathrm{C}$ & 0.085 & 3.2 \\
\hline Content of organic substances, \%, no more & 3.2 & $\mathrm{NC}$ \\
\hline $\begin{array}{l}\text { Group of combustibility (without covering } \\
\text { a foil) }\end{array}$ & $\mathrm{NC}$ & $1200 \times(20-100)$ \\
\hline Length $*$ thickness, mm & $1200 \times(20-100)$ & 1824 \\
\hline Pipe diameter (inside diameter), mm & $18-324$ & $18-324$ \\
\hline
\end{tabular}

Use of the mineral wool cylinders allows to provide isolation of pipelines with the liquids and gases, which are especially transported with high speed. Cylinders without a covering belong to KM0 (NC) non-combustible materials, with the covering - to KM1 (C1) group. Cylinders possesses elasticity and can to recover its shape after application of heavy loads. The spirally wound cylinders are more technological in production and have a higher degree of a factory readiness.

\section{Methods}

Research objective was a development of a products based on mineral fiber for thermal insulation of the pipelines and thermal units working in a temperature interval up to $600{ }^{\circ} \mathrm{C}$.

Approbation of the epoxy thermosetting composition with a latent hardener as a binder together with mineral wool fibers produced by the ROCKWOOL Company and optimization of the modes of thermal treatment of mineral wool products was a research problem. Researches were started in four directions. Receiving mineral fibers without sizing agent and without factory binder (phenol formaldehyde binder is entered into mineral wool carpet at its sedimentation after fiber formation). Development of the mechanism of insertion of a binder in the laboratory conditions. Development of the modes of convective thermal treatment of mineral wool products and development of a technique of the choice of parameters of thermal treatment by method of a motion of the heat carrier through a mineral wool carpet. 
Mechanics of a burning out binder is in alternate drying of mineral fiber up to the constant weight for the purpose of removal of factory phenol formaldehyde binder. On a baking sheet placed the cut-off pieces of a mineral wool mat (approximate size 250x150x50 mm) cutted from factory standard size mat 1000x600x50 of "ROCKWOOL Heat insolation. Then a baking sheet was located in the chamber of "SNOL" dryer with an interval of temperature of roasting from $10{ }^{\circ} \mathrm{C}$ to $400{ }^{\circ} \mathrm{C}$ with the exposed temperature of "drying" $350{ }^{\circ} \mathrm{C}$ for 1 hour. Then the baking sheet was taken out and cooled off on a metal plate (15 minutes). Then it was weighed for the purpose of clarification of mass change of samples. After 5 repetitions the mass of fiber became constant and equal 187,825 grams.

According to the program of researches, properties of the epoxy thermosetting binder TPK-14 about a possibility of its application as binder for production of mineral wool products have been studied earlier. The composition TPK-14 is developed by "MMP-IRBIS" and VIAM together with IHF Russian Academy of Sciences as domestic analog of glue composition of ASAHI CA-35. After removal of phenol formaldehyde binder to mineral fibers has been added the epoxy thermosetting binder with a latent hardener (TPK-14) in the amount of $3 \%$ of the turned-out mass of fiber (187,825 grams) 3,5 grams. The prepared samples have passed thermal treatment in the same "SNOL" dryer chamber at a temperature of $125^{\circ} \mathrm{C}$ for 6 minutes.

The technique of the choice of parameters of thermal treatment was based on earlier applied researches of the modes of thermal treatment of flat mineral wool products. As a result of a full-scale experiment transitional coefficients from flat products (a mineral wool carpet) to cylindrical have been established and as result of calculations the nomograms that allowing to solve technology problems are received.

\section{Results}

Thermal treatment of spirally wound mineral cylinders [7] is that the heat carrier is enters to a perforated rolling pin (on which the mineral wool layer is wound), and heating of a fibrous material is applicate by motion of the heat carrier through a mineral wool layer. Optimization of this process is connected with regulation of properties of a mineral wool layer and, first of all, the hydraulic resistance of a mineral wool carpet.

Analytical impact assessment of characteristics of the mineral wool cylinder structure and parameters of its thermal treatment was applicate on the basis of use of a model of the movement of a compressible fluid (heat carrier) through the porous environment (a mineral wool layer) [7].

The made experiment has shown that hydraulic resistance of mineral wool products of a cylindrical form $(\Delta \mathrm{P} \mu)$ can be determined on the basis of calculation of hydraulic resistance of a flat mineral wool carpet of the corresponding density $(\Delta \mathrm{P})$ (figure 1) and taking into account the value of parameter of $\mathrm{K} \mu$, by dependence:

$$
\Delta P_{\mu}=\mathrm{K}_{\mu} \Delta P
$$

Parameter of $K \mu$ is function of characteristics of a mineral wool product of a cylindrical form and is defined from equation:

$$
K_{\mu}=\frac{a v_{0}\left(\frac{H}{r_{0}+H}\right)+b \ln \left(1+H / r_{0}\right)}{b+a v_{0}} \times \frac{r_{0}}{H}
$$




$$
\text { At }: a=0,89 S \rho \frac{\left(1-m^{\prime}\right)^{1 / 3}}{m^{\prime 3}} ; b=0,6 \mu S^{2} \frac{1}{m^{\prime 3}\left(1-m^{\prime}\right)^{2 / 3}}
$$

Internal radius of the cylinder $\left(r_{0}\right)$ is equal to diameter of a perforated rolling pin. Thickness of a layer of coiling of isolation $(H)$ is defined from requirements to heat physical characteristics of insulating system. The specific surface of fiber $(S)$ and porosity $\left(m^{\prime}\right)$ of a mineral wool carpet are established on test results in factory laboratory. Heat carrier velocity at the entrance to the carpet is adjustable parameter, density $(\rho)$ and viscosity $(\mu)$ of the heat carrier are functions of its temperature and can be accepted as table values (for the warmedup air or combustion gases).

For convenience of engineering calculations, analytical dependences (1 and 2) are presented in the graphic form (figure 1,2), and determine hydraulic resistance as work of basic functions and coefficients:

$$
\begin{gathered}
\Delta P=\Delta P_{v} \cdot K_{\rho} \cdot K_{C} \\
\Delta P_{\mu}=\Delta P \cdot K_{H} \cdot K_{r_{0}} \cdot K_{S} \cdot K_{m^{\prime}} \cdot K_{t}
\end{gathered}
$$

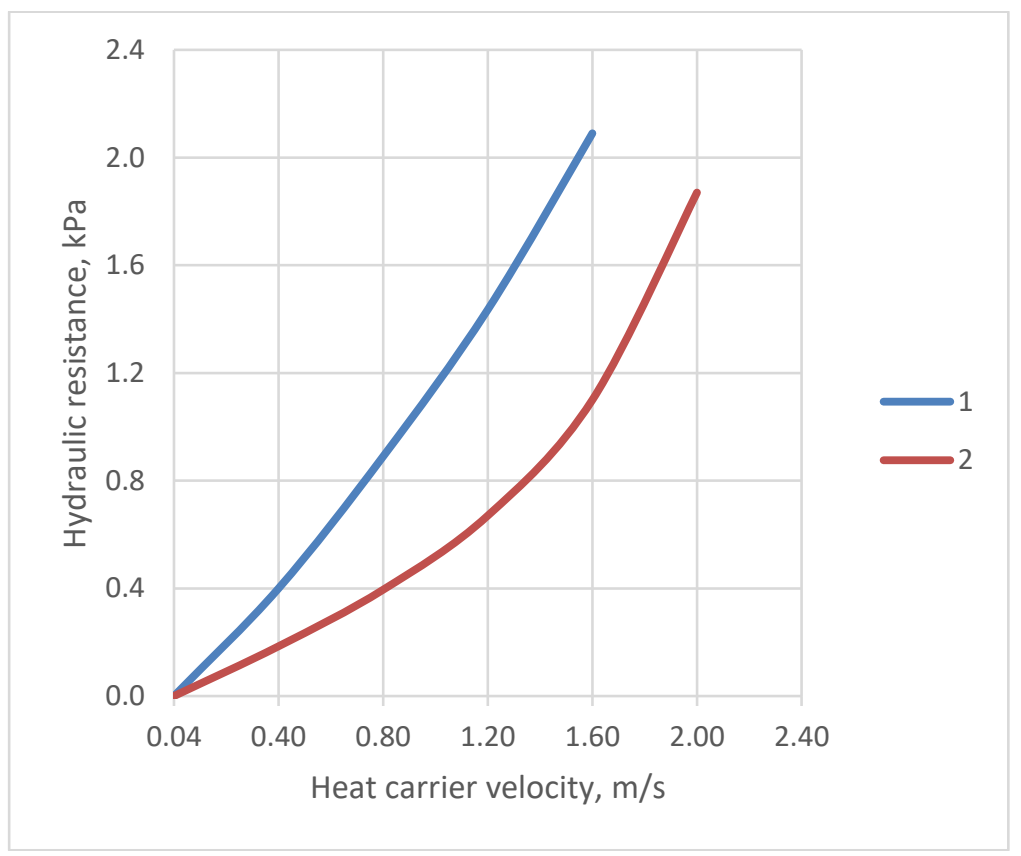




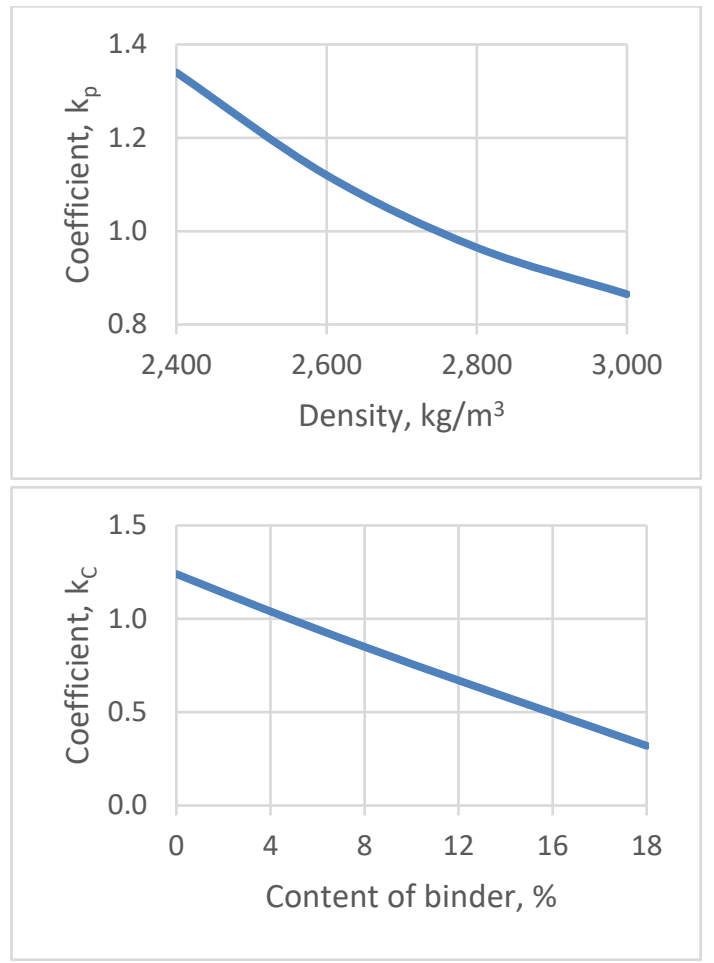

Fig. 1. The abacus for determination of hydraulic resistance of a mineral wool carpet: 1 - carpet of linear structure; 2 - a carpet of volume oriented structure

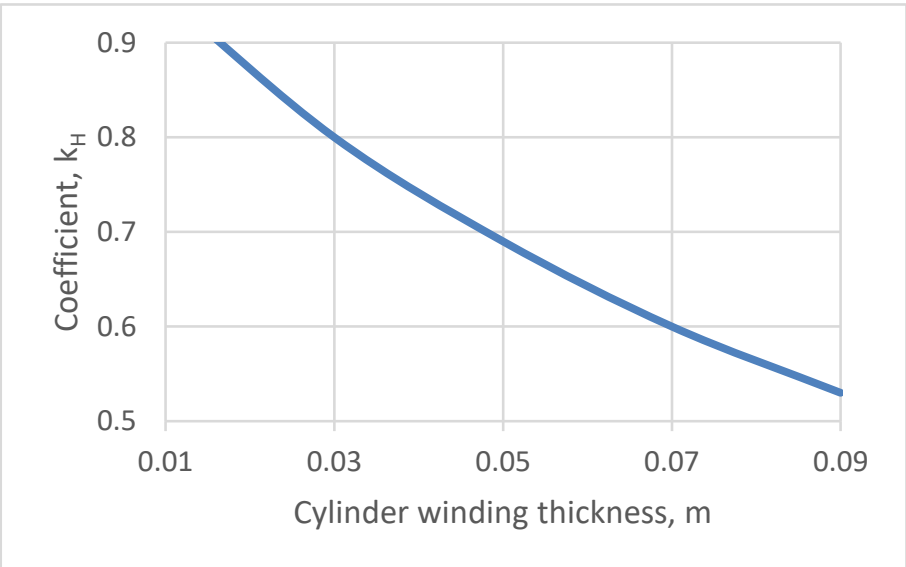




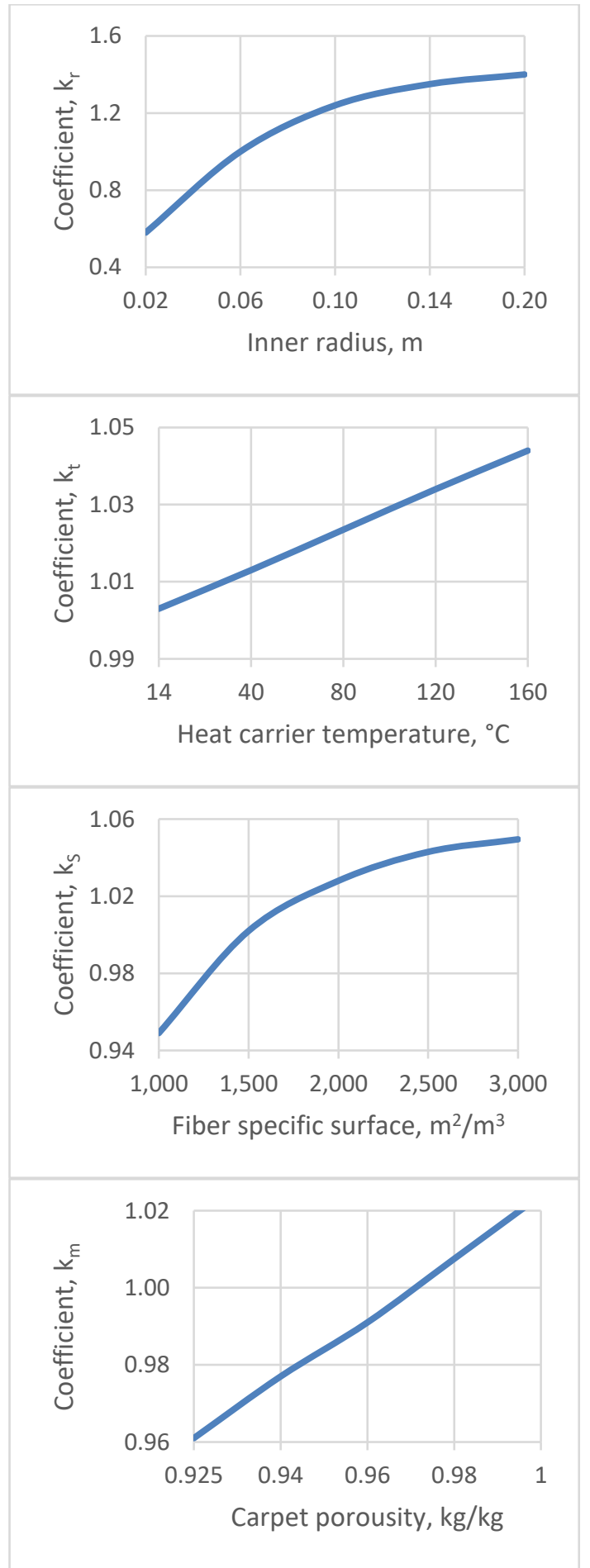

Fig. 2. The abacus for determination of parameter of $\mathrm{K} \mu$ 


\section{Discussion}

At thermal treatment of a mineral wool carpet, the lengthwise current of the heat carrier in a perforated rolling pin is followed by simultaneous distribution of the heat carrier through sidewalls. That mean the movement of a heat carrier flow happens with changing of consumption along a way by analogy with the supply collector. At the same time the outflow of the heat carrier from a rolling pin (length of 1-2 m) happens in a layer of a mineral wool carpet with different permeability. Therefore, the outflow of gas from perforated walls of a rolling pin will be defined by not only characteristics of openings and excessive pressure in a rolling pin, but also structural and geometrical characteristics of the mineral wool cylinder and its hydraulic resistance.

The intensive modes applied to thermal treatment of mineral wool cylinders with high speeds of a blowing ( $\mathrm{Re}$ value for the outflow from rolling pin openings not less than $10^{5}$ ) allow to accept value of coefficient of the outflow to constants longwise of a rolling pin.

The outflow of the heat carrier through perforation of sidewalls of a rolling pin will be undoubtedly influenced by heat carrier flow turbulences, which is a radial component of the movement. However, it is not possible to consider it. It is also impossible to estimate change of hydraulic resistance of a mineral wool carpet longwise of a rolling pin due to randomness of an arrangement of fibers and caverns and their diameters distributions.

At the outflow of the heat carrier from side openings in porous material at some distance separate streams of the heat carrier connect, forming a continuous flow. Disclosure of streams happens under the certain angle depending on permeability of the environment for a mineral wool carpet the angle of disclosure of a stream is rather big and reaches the $50^{\mathrm{g}}$ therefore with a small diameter of openings formation of a continuous flow comes to the end at small removal from a rolling pin wall.

The experimental influence assessment of perforation distribution to characteristics of a flow of the heat carrier, show that increase of perforation rate leads to more dramatic change of static pressure longwise rolling pin. With the outflow of the heat carrier into a layer of a fibrous material, the deviation of flows speeds from the uniform distribution values is significantly reduced. When blowing a rolling pin with a layer of a fibrous material, the maximum deviation is $22,5 \%$, and without a layer $-60 \%$.

The obtained data and mathematical model of process have been used for creating algorithm of the computer program. The program is made at the $\mathrm{C \#}$ programming language is intended for calculation of parameters of thermal treatment of mineral wool cylinders which is made by motion of the heat carrier arriving from a perforated rolling pin through a surface of a fibrous product of a cylindrical form. A basis of algorithm of the program is the mathematical model of process.

The application of the suggested methods allows to optimize power consumption due to reduction of the electric power consumption at the drive of the blow equipment and decrease in heat consumption on warming up of mineral wool spirally wound cylinders, along with increase of uniformity of thermal treatment of mineral wool cylinders. Besides, increase of uniformity of warming up of a mineral wool carpet improves uniformity of a curing of binder in material that will reduces risks of destruction of mineral wool insolation and will prevent appearance of the defects caused by incomplete polycondensation of a binder.

\section{Conclusions}

Mineral wool cylinders (semi-cylinders) apply to insolation of pipelines with small pipe diameter from 12 to $273 \mathrm{~mm}$. At isolation of pipes of bigger diameter segments or mats are used. Similar systems of isolation apply to thermal insulation of pipelines on any objects: multifunction shopping centers, private housing construction, apartment buildings, factories, 
objects of the food industry and so on. The main requirements to systems of insolation are preservation of technical properties for all declared exploitation term, an elimination of outside moisture penetration and prevention of condense inside of a system. For the durability of these products, an important factor is completeness of curing of a binder

Durability of materials is defined by properties of mineral fiber, type of binder and completeness of its curing in material. Power costs of production are connected with receiving fusion, its processing into a fiber and thermal treatment of the formed raw carpet. Modern thermal insulation products made from the mineral stone fiber possessing high chemical resistance. As the binder in that products is apply neutralized phenolic alcohols that also have high resistance in the cured state, but they are toxic and are not always cured in a product completely. In hot pipelines and especially at condition of increased humidity of a thermal-insulation layer a destruction of the contact zone "fiber-binding" may lead to releasing of harmful substances (phenols).

Application of binder with the latent modifying components, cured at temperatures up to $150^{\circ} \mathrm{C}$, on the one hand promotes increase in extent of curing binding, and on the other hand provides decrease in power costs of thermal treatment of mineral wool cylinders.

\section{References}

1. D. Tuchaev, E. Zarmanyan, E. Petrovskiy, A. Zemlyanko, K. Ivanov, A. Zhukov. Thermal insulation systems for the Arctic. FORM 2018. IOP Conf. Series: Materials Science and Engineering (2018) doi:10.1088/1757-899X/365/3/032015032041

2. A. D. Zhukov, T. V. Konoval'tseva, E. Yu. Bobrova, E. A. Zinovieva, K. K. Ivanov, Thermal insulation: operational properties and methods of research. IPICSE. Published online: 14 December 2018. DOI: https://doi.org/10.1051/matecconf/201825101016

3. V. I. Livchak, A realistic approach to energy efficiency in the existing housing stock of the city, Magazine Energy Saving, 5, pp. 14-18 (2002)

4. P. M. Zhuk, A. D. Zhukov, Normative legal base of environmental assessment of building materials: prospects for improvement, Ecology and industry of Russia, 4, pp. 52-57 (2018)

5. Yu. L. Bobrov, Express method and laboratory equipment for quality evaluation of porous materials, Abstracts of the report of the international scientific-practical conference, "Modern methods of quality control problems and their solutions", pp. 4344 (1985)

6. S. E. Shmelev, Ways to choose the optimal set of energy-saving measures. Building Materials, 3, pp. 7-9 (2013)

7. I. Gnip, S. Vaitkus, V. Kersulis, S. Vejelis, Long-term prediction of creep strains of mineral wool slabs under constant compressive stress. Mech Time Depend Mater, 16, pp. 31-46 (2012) DOI 10. 1007/s11043-011-9152.

8. I. Ya. Gnip, S. I. Vaitkus, Analytical description of mineral wool creeping deformation during prolonged compression, Building materials, 11, pp. 57-62 (2013)

9. V. I. Telichenko, D. V. Oreshkin, Materials science aspects of geo-ecological and environmental safety in construction, Ecology of urbanized territories, 2, pp. 31-33 (2015)

10. I. V. Bessonov, A. V. Starostin, V. M. Oskina, About dimensionally stable fibrous insulation, Journal Herald MSUCE, 3, pp.134-139 (2011) 
11. A. D. Zhukov, E. Yu. Bobrova, D. B. Zelenshchikov, R. M. Mustafaev, A. O. Khimich, Insulation systems and green sustainable construction, Advanced Materials, Structures and Mechanical Engineering. Volumes 1025 - 1026, pp. 1031-1034 (2014)

12. B. M. Rumyantsev, A. D. Zhukov, Principles for the creation of new building materials [Electronic resource], 3(23) (Internet-Bulletin VolgGASU, 2012)

13. A. D. Zhukov, T. V. Smirnova, D. B. Zelenshchikov, A. O. Khimich, Thermal treatment of the mineral wool mat, Advanced Materials Research, Vols. 838-841, pp. 196-200 (Switzerland, 2014)

14. B. M. Rumyantsev, A. D. Zhukov, D. B. Zelenshikov, A. S. Chkunin, K. K. Ivanov, Yu. $\mathrm{V}$. Sazonova, Insulation systems of the building constructions, in: MATEC Web of Conferences, 86 (2016) DOI: 10.1051/matecconf/20168604027.

15. I. V. Bessonov, A. D. Zhukov, E. Yu. Bobrova, Building systems and features of the use of thermal insulation materials. Magazine Housing Construction, 7, pp. 49-52 (Moscow, OOO RIF, 2015)

16. V. R. Hlevchuk, I. V. Bezsonov, On current thermal performance of mineral wool, Problems of construction of thermal physics, climate systems, and energy efficiency in buildings pp. 127-135 (Moscow, NIISF, 1998)

17. B. M. Rumiantcev, A. D. Zhukov, E. Yu. Bobrova, I. P. Romanova, D. B. Zelenshikov, T. V. Smirnova, The systems of insulation and a methodology for assessing the durability, MATEC Web of Conferences, 86 (2016). DOI: http://dx.doi.org/10.1051/matecconf/ 20168604036.

18. E. Arquis, C. Cicasu, Convection phenomen in mineral wool in-stalled on vertical walls, Proceedings of the International scientific-practical conference "Effective heat and sound insulating materials in modern construction and housing and communal services." p. 18-21 (Publishing house MSUCE, Moscow, 2006) 